\title{
Integrating real-world clients in a project management module.
}

\author{
ZARB, M., YOUNG, T. BALLEW, W.
}

2019

(c) Owner/Author 2019. This is the author's version of work. It is posted here for your personal use. Not for redistribution. The definitive Version of Record was published in Proceedings of the 24th Innovation and technology in computer science education annual conference, 15-17 July 2019, Aberdeen, UK, http://dx.doi.org/10.1145/3304221.3325559 


\section{Integrating Real-World Clients in a Project Management Module}

\author{
Mark Zarb \\ School of Computing Science and \\ Digital Media \\ Robert Gordon University \\ Aberdeen, United Kingdom \\ m.zarb@rgu.ac.uk
}

\author{
Tiffany Young \\ School of Computing Science and \\ Digital Media \\ Robert Gordon University \\ Aberdeen, United Kingdom \\ t.young3@rgu.ac.uk
}

\author{
William Ballew \\ James Fisher Digital \\ Barrow-in-Furness \\ Cumbria, United Kingdom \\ w.ballew@james-fisher.co.uk
}

\begin{abstract}
Graduates in CS are required to have a background in project management, but often this is taught as a theoretical module, with little "real-world" relevance. A Project Management module within the School of Computing Science and Digital Media at the Robert Gordon University has been redeveloped around the idea of having a real client interact with the class throughout the module, to positive comments from staff and students alike.
\end{abstract}

\section{CCS CONCEPTS}

-Social and professional topics $\rightarrow$ Computing education; Student assessment.

\section{KEYWORDS}

project management, client, assessment

\section{INTRODUCTION}

Traditionally, teaching within Higher Education Institutes happens within the confines of the classroom, lecture hall or laboratory. This separates the students' learning from the context and application of work-based activities. Having these as distinct entities disadvantages students from applying their learnings within a "real-world" context [1], specifically within more theoretical subjects, such as project management.

A curriculum redesign within the School of Computing Science and Digital Media at the Robert Gordon University provided the opportunity for a project management module to be refreshed.

Project Management and Software Engineering is a module taught to students within the School in their third year (in a four-year degree programme). Historically, this was paired with a partner module to distinguish between development and project management. Whilst this method had its advantages, it was not allowing students to properly experience complete software development lifecycles in a "real world" context, as students would often treat the two modules separately, choosing to complete the bulk of the project management and accompanying documentation after the code was completed. Furthermore, the project "client" was typically a lecturer with whom they had had previous interactions, thus diluting this very important experience and learning opportunity.
The module was revamped as part of a curriculum redesign in 2017 and redeveloped to be a stand-alone module with its own project client. Whilst software development is a required component of this module, the summative assessment is based solely on the team's interactions with the client, and their produced documentation (e.g. Gantt charts, sprint backlogs, meeting minutes, class diagrams, etc.). The "new" version of the module has been taught three times, each with a different client - but always following the same format:

The client is asked to devote a number of meeting points (a minimum of four over a ten-week teaching period) where they interact with the students throughout the semester in an agile manner this time is always restricted, thus being more representative of a "real world" situation. The meeting points, during which the client and module lecturers are available to give formative feedback, are typically as follows:

- First meeting: client gives a description and background of the real world problem to the entire class

- Second meeting: client meets with individual teams to sign off on their proposed solution

- A number of agile sprints follow, depending on client availability

- Final meeting: client signs off on student progress

The students, self-sorted in small groups, therefore inherit several responsibilities in the spirit of agile project management:

(1) To work in sprints around the client's available time;

(2) To learn to speak in a non-technical language (recent clients were located outside the technology sector);

(3) respect the time the client could give them (typically 10 minutes a fortnight) and learn to maximize this time.

\section{REFLECTION}

The introduction of a client-facing approach has been part of the module for the past three iterations and has been met with positive feedback from the students, who suggest that this module is no longer viewed as a theoretical/detached module, but one in which they are gaining important and relevant employability skills.

\section{REFERENCES}

[1] Hugh McCabe. 2016. Integrating Work Experience into the Digital Media Curriculum: A Case Study. (2016) 